\title{
Authenticity, Lawlessness and the Lack of Aesthetics in Nan Goldin and Larry Clark's Photography
}

\author{
Qiao Fan \\ University of New South Wales, Australia \\ Email: qiao.fan@unswalumni.com
}

\begin{abstract}
Nan Goldin and Larry Clark documented the real life of degenerate groups in the late 1900s in the United States by photographing. Coming from similar backgrounds, authenticity and lawlessness run through Goldin and Clark's photography, and the lack of aesthetics in their works exactly reinforces the authenticity and lawlessness of them. The article analyses Goldin and Clark's photography styles from their backgrounds and skills, and takes examples from Goldin's The ballad of sexual dependency, The devil's playground and Clark's Tulsa to introduce and compare the authenticity and lawlessness the photographers manifest in their photography.
\end{abstract}

Keywords: photography, Nan Goldin, Larry Clark, authenticity, lawlessness, aesthetics

Photography is invented to record moments in one's life, photographers Nan Goldin and Larry Clark apply photography as a medium to record marginalised groups and objects in the society, the astonishing contents of their works expand people's horizon of the degenerate groups in the society, bring the photographers fame in the field, and influenced a generation of photographers. Under the prosperous surface of the society of the United States in the late 1900s, drugs, guns, homosexuality, promiscuity, transvestism, fetishism, AIDS and domestic violence sprawl across the superpower. Nan Goldin and Larry Clark used to be members of such groups. In an authentic way, as insiders, they take photographs for them to record their non-mainstream life styles. The lawlessness of the contents and random compositions are distinctly shown in their works, nude bodies, guns, drugs are all frequent components of the pictures. However, though the aesthetics of their works may not be very well presented, the absence of aesthetic value precisely reflects the authenticity and lawlessness of the works.

Growing up with similar circumstances, Nan Goldin and Larry Clark's works overlap on similar themes. Goldin was born in a well-to-do middle-class Jewish family in Washington, D.C. in 1953, she is the youngest among the four children of her parents'. She was expelled from a boarding school when she was 14 years old due to violating school rules. She then left home for irreconcilable conflicts with her family. She lived in communes and foster homes and went to a community school. In the school, she learnt photography and gradually became obsessed with it. Goldin took photographs for everything around her for keeping the moments, that is partly because her sister did not leave her much memory after her suicide when Nan Goldin was 11 years old, Goldin does not want to lose any valuable moments any more (Als 2016). She asserts, "photography saved my life; every time I go through something scary, traumatic, I survive by taking pictures", photography "is about keeping a record of the lives I lost, so they cannot be completely obliterated from memory" (Foto tapeta 2003). Goldin used to be a drugs addict and hung around with drug users and homosexual people, so that most of her works are about these marginalised groups in the society. Similar to Goldin, the experience of Larry Clark's childhood largely disappointed him, he was not even appreciated by his own father. Thus, he started using drugs to calm himself down and consorted with gun-toting friends, had sex with strung-out girlfriends when he was a teenager, which is how he has much enough experience about subcultures such as drugs, violence and underage sex (O’Hagan 2014). Clark had access to photography at an early age for helping in his family's commercial photographic business, then he went to the Layton School of Art in Milwaukee, studied photography with photographer Walter Sheffer (Hostetler 1999, pp. 211-212). The similar backgrounds result in the styles and themes of Nan Goldin and Larry Clark's works have a great deal of similarities, they both record certain degenerate or abnormal hardcore subcultures (e.g. drugs, violence, sex and gays) with their cameras. The unusual scenes are unreservedly shown from their inside views in their photographs. Specially, what is also worth mentioning is as a senior, Larry Clark's works inspired Nan Goldin, in other words, Clark's works put Goldin onto the right track of photography (Beyfus 2009).

Authenticity and lawlessness are integrated within Nan Goldin's The ballad of sexual dependency (1986). The ballad of sexual dependency is a series of photographs presented as a book and slide shows, they were taken by Nan Goldin between 1979 and 1986 and first brought her fame. The title "The ballad of sexual dependency" is derived from a song composed by Bertolt Brecht, titled "The ballad of sexual dependency" in the Three penny opera, the piece of music is also applied in the slide shows as the opening song (Goldin and Holborn 1986, pp. 38-47). Goldin associates with the people 
first, then photographs them. "The ballad" is a visual diary that records Goldin's extended family - her friends, lovers and herself, many of whom are drug addicts or queers. They partied, made love and fought, the lawless and realistic images are like an epitome of the degenerate subcultures around New York City in the 1980s. As herself states, "I didn't care about good photography, I cared about complete honesty" (Behrmann n.d.). "I don't select people in order to photograph them; I photograph directly from my life", she says, "these pictures come out of relationships, not observation" (Goldin 1996). The daily life of her AIDS-infected friend till her death, the clearly contrasted bruises on her face in her famous self-portrait "Nan One month after being battered" (1984) both vividly depict the authenticity of figures and their lives. Although we can hardly find much beauty from her works, the random, lawless composition makes up a sense of authenticity, which brings viewers extremely intense impact. Through the authenticity, viewers not only gain a better understanding of the subcultures, but feel the wild atmosphere of their lives which is what most of people rarely notice.

Technic devices contribute to the authenticity of photographs, at the same time, they also play a role in aesthetic to enhance the authenticity. "Blur" and "snapshot" are used in many of Goldin's photographs. The term "blur" means "the whole or a part of the picture is out of focus and thus indistinct" (Skodbo 2007, p. 47). In The ballad, "blur" is used in photographs like "The hug" (1980) by photographing a moving subject or by "moving the camera with 'too slow' shutter speed" to create a sense of hectic movement (Skodbo 2007, p. 48). "Snapshot" means a photograph that is taken in a hurry to catch a transient scene on film (Skodbo 2007, p. 47). Parts of objects may be at the edges of photographs or even cut off by the frame to create an atmosphere of disarray. "Blur" and "snapshot" both make photographs look more meaningful and realistic. However, in terms of general aesthetics, not much aesthetic is revealed in most of the randomly composed photographs in Goldin's works. But the core information the photographs convey is precisely the authenticity, they would not look this authentic if the components and clolours are nicely composed in terms of aesthetics, that would eliminate the reality of real life. The ballad "remains a benchmark for all other work in a similar confessional vein" (O'Hagan 2014). In terms of its influence, it "would come to influence a generation of fledgling photographers, who fell into her truth-telling wake" (Davies 2014), it "forged a genre, with photography as influential as any in the last 20 years" (Tillman 2003).

Goldin's authenticity and lawlessness are remained in The Devil's playground (2003). The Devil's playground is another series of over 500 photographs taken by Goldin from America to Europe, from the 1970s to the 2000s, which record daily lives of the people and objects around her, drugs, AIDS, sex are still indispensable contents in this collection. It continues Goldin's lawlessness and authenticity, the lawlessness seems more intense than in her previous works, so that the sensitive content in the "Klara and Edda belly-dancing" (1998) was even accused for child pornography (Withersworldwide 2008). However, compared to her previous works, difference and artistic growth are shown in The Devil's Playground, more aesthetic values can be seen in this collection. "Blur" and "snapshot" still appear in some of the photographs, she also used ambient light to create smoky, dark tones without on-camera flash to make photographs look very sensual and evocative (Bowie 2005). Another difference is that she photographed more unpopulated spaces, empty beds and blank rooms instead of human figures appearing in most of the collection as some of her previous ones. Specially, some aesthetic photographs are collected in this photography book. For instance, "Breakfast in Bed, Hotel Torre Di Bellosguardo, Florence 1996" (1996) depicts a peaceful painting-like picture. In contrast to the parted white curtains and the clean, white overlapped cloths, the stand-out colours of the croissants, fruit, eggs, teakettle and teacups stimulate people's appetite. It is clear to see, with time elapsing, Goldin's photography becomes increasingly more experiential and skilful.

Same as Goldin's works, Larry Clark's Tulsa (1971) also authentically conveys outlaw life styles of people of crazy subcultures. Tulsa is a portfolio of black-and-white photographs Clark took for his friends in suburban Tulsa, Oklahoma from 1963 to 1971. As Clark himself states, "I just happened to have my camera and be photographing my friends. It was totally innocent, there was no purpose to the photographs. There was a purity to them that wasn't planned, it was realism" (Van Sant 1995). The lawless, heterodox and astonishing life styles of degenerate adolescents in the 1960s in the middle of the USA are authentically recorded by Clark's camera. Drugs, guns, sex are realistically portrayed through his photographs. Clark's works created a style that is "a blurring of the lines between voyeurism and intimate reportage, between honesty and exploitation" (O’Hagan 2014). He photographs people and objects from his own experience, all the shocking scenes were realities existed around himself. Authors of The Photobook Volume 1, Martin Parr and Gerry Badger describes that the "incessant focus on the sleazy aspect of the lives portrayed, to the exclusion of almost anything else - whether photographed from the 'inside' or not - raises concerns about exploitation and drawing the viewer into a prurient, voyeuristic relationship with the work" (ibdi.). The style is later followed by photographers such as Nan Goldin, Corinne Day and Antonie D'Agata.

The lack of aesthetics enhances the authenticity of the pictures in Tulsa. "Snapshots" and "blurs" also exist in many photographs in Tulsa to construct a random atmosphere for its authenticity. Clark explains, 'for me there are no rules. I think I learned that from artists - from painters and sculptors. It took photography a while to catch up to them (Goethals 
2010). The untidy rooms, undisguised bodies, tilted compositions generally do not contain much aesthetic value. But life itself, especially the lives of the abandoned youngsters are not often beautiful. The absence of aesthetic exactly reflects the authenticity of the real life that the photographs depict.

In conclusion, Larry Clark and Nan Goldin's works portray similar degenerate groups of people who are neglected by the mainstream society. Authenticity and lawlessness are the cores of their photography works. Through their cameras, the dark and hidden side of the society is undisguisedly shown to the public in an authentic way. The violence, sex and drugs shown in the photographs reveal depraved subcultures in the United States. The lack of aesthetics, as well as the utilisation of "snapshot" and "blur" and random-looking compositions assist to intensify the authenticity and lawlessness of their photography works. Their photography works narratively tell shocking or distressing stories about the people and objects and influence the world of photography as an unordinary style.

\section{References}

[1] Als, H 2016, Nan Goldin's life in progress, The New Yorker, viewed 20 July 2021, <https://www.newyorker.com/magazine/2016/07/04/nan-goldins-the-ballad-of-sexual-dependency>.

[2] Behrmann, K n.d., Nan Goldin The ballad of sexual dependency, The art of creative photography, viewed 21 July 2021 , $<$ http://artofcreativephotography.com/famous-photographers/nan-goldin-the-ballad-of-sexual-dependency/>.

[3] Beyfus, D 2009, Nan Goldin: unafraid of the dark, The telegraph, viewed 20 July 2021, <http://www.telegraph.co.uk/ culture/photography/5648658/Nan-Goldin-unafraid-of-the-dark.html $>$.

[4] Bowie, C 2005, Review: The devil's playground by Nan Goldin, Spot: The journal of the Houston Center of Photography, fall.

[5] Davies, L 2014, Nan Goldin: from post-punk parties to parental love, The Telegraph, viewed 21 July 2021, <http:// www.telegraph.co.uk/culture/photography/10746151/Nan-Goldin- from-post-punk-parties-to-parental-love.html $>$.

[6] Foto tapeta 2003, Nan Goldin interviewed by Adam Mazur and Paulina Skirgajllo-Krajewska, viewed 21 July 2021 , $<$ http://fototapeta.art.pl/2003/ngie.php $>$.

[7] Goethals, R 2010, X-rated in Paris, Forward Thinking museum, viewed 22 July 2021, < https://zh.scribd.com/document/68979956/X-Rated-in-Paris>.

[8] Goldin, N 1995, I'll be your mirror, Episode 1, dvd, British Broadcasting Corporation, London.

[9] Goldin, N 1996, From the book - The ballad of sexual dependency, American Suburb X, viewed 21 July 2021, <http:// www.americansuburbx.com/wp-content/uploads/2012/09/nan-goldin-ballad-of-sexual-dependency.pdf>.

[10] Goldin, N and Holborn, M 1986, Nan Goldin's Ballad of sexual dependency, Aperture, No. 103, Fiction and metaphor.

[11] Hostetler, L 1999, Reflections in a Glass Eye: Works from the International Center of Photography Collection, Bulfinch Press in association with the International Center of Photography, New York.

[12] O’Hagan, S 2014, Nan Goldin: "I wanted to get high from a relly early age”, The Guardian, viewed 21 July 2021 , $<$ https://www.theguardian.com/artanddesign/2014/mar/23/nan-goldin-photographer-wanted-get-high-early-age>.

[13] Skodbo, T 2007, Nan Goldin: The other side - photography and gender identity, dissertation, University of Oslo.

[14] Tillman, L 2003, Art; a new chaper of Nan Goldin's diary, The New York times, viewed 21 July 2021, <http://www. nytimes.com/2003/11/16/books/art-a-new-chapter-of-nan-goldin-s-diary.html>.

[15] Van Sant, G 1995, Larry Clark, Shockmaker, Harmony-korine, viewed 22 July 2021, <http://www.harmony-korine. com/paper/int/lc/shockmaker.html>.

[16] Withersworldwide 2008, Nan Goldin - contemporary art works seized from an English gallery, viewed 22 July 2021 , $<$ https://www.withersworldwide.com/es-es/nan-goldin-contemporary-art-works-seized-from-an-english-gallery>. 